\title{
Age-specific mortality and transport of larval walleye pollock Theragra chalcogramma in the western Gulf of Alaska
}

\author{
Sarah Hinckley ${ }^{1}$, Kevin Bailey ${ }^{1}$, Susan Picquelle ${ }^{1}$, Mary Yoklavich ${ }^{2}$, Phyllis Stabeno ${ }^{3}$ \\ ${ }^{1}$ NOAA, National Marine Fisheries Service, Alaska Fisheries Science Center, 7600 Sand Point Way NE, Seattle, \\ Washington 98115 , USA \\ ${ }^{2}$ NOAA, National Marine Fisheries Service, Pacific Fisheries Environmental Group, Southwest Fisheries Science Center, \\ PO Box 831, Monterey, California 93942, USA \\ ${ }^{3}$ NOAA, OAR, Pacific Marine Environmental Laboratory, 7600 Sand Point Way NE, Seattle, Washington 98115, USA
}

\begin{abstract}
A field study was conducted in May 1988 to estimate mortality rates of individual cohorts of larval walleye pollock Theragra chalcogramma in Shelikof Strait, Gulf of Alaska. Two surveys of the area of larval distribution were done $12 \mathrm{~d}$ apart and daily mortality rates estimated from changes in abundance of each cohort. This study was designed to minimize potential sources of bias to mortality estimates, such as larval extrusion or escapement from sampling gear, advective or diffusive gain or loss of larvae into or out of the sampling area, the uncertainty incurred by the use of length as a proxy for age, and the often erroneous assumption of constant production and mortality rates. The agespecific mortality rates from this study were low compared to rates previously estimated for larval walleye pollock. Four significant mortality estimates, ranging from 0.041 to $0.076 \mathrm{~d}^{-1}$, came from among the youngest cohorts. The low larval mortality rates in 1988 coincided with very calm ocean conditions. Larval drift rates estimated in this study were coherent with the movement of a satellite-tracked drift buoy and averaged 3.1 to $3.9 \mathrm{~cm} \mathrm{~s}^{-1}$, which is comparable to rates reported from other studies.
\end{abstract}

\section{INTRODUCTION}

One of the most challenging problems in marine research is the estimation of mortality rates of organisms. This is particularly the case with planktonic early life stages of marine fishes due to the broad spatial and temporal scales of their distribution, their movement with currents, other sampling difficulties, and nonconstant birth rates (i.e. often peaked spawning cycles). It is frequently inappropriate to assume a stable age distribution and constant mortality rates to justify use of catch curve analysis (Ricker 1975, Hewitt \& Methot 1982). Knowledge of mortality rates of marine fish eggs and larvae is a key to understanding the recruitment process of marine fishes because, for many species, the magnitude of recruitment may be established during early life stages (Houde 1987, Sundby et al. 1989, van der Veer et al. 1990). Accurate measurement of the magnitude and variability of mortality rates in the field is required to assess the causes and processes of mortality, such as predation and nutrition. Data on interannual variation in mortality rates can also be instrumental in forecasting year-class success.

We describe a method used to estimate the daily mortality rates for larval fishes from a population characterized by highly aggregated spawning that occurs over a short period of time. Walleye pollock Theragra chalcogramma spawning in Shelikof Strait (Alaska) occurs largely within a 1 mo period (Kirn \& Kendall 1989, Kendall \& Picquelle 1990, Picquelle \& Megrey in press). Larvae live in the upper $100 \mathrm{~m}$ of the water column and are advected to the southwest for several weeks in the Alaska Coastal Current (ACC) (Hinckley et al. 1990, Kendall \& Picquelle 1990) and larval distributions are relatively predictable in time and space.

We have identified cohorts of larval walleye pollock from their hatch-date distributions as determined from daily growth increments on otoliths and have sampled 
the population twice, ca $12 \mathrm{~d}$ apart, to estimate mortality rates for each cohort. Larval transport was estimated from movement of several main patches of cohorts, from the displacement of centroids of the entire larval distribution, and from a satellite-tracked drift buoy (drogued at $40 \mathrm{~m}$, the depth of highest larval abundance) released in the center of one of the main larval concentrations. Advection of larvae across the boundaries of the sampling grid was estimated from a model of advection and diffusion.

\section{METHODS}

Survey design. Data from larval walleye pollock surveys of Shelikof Strait in 1986 and 1987 were examined to set the overall boundaries of the sampling area used in the present study and to estimate the likely abundances of larvae. An analysis of these data was used to estimate the number of stations needed to detect a reasonable minimum mortality rate. A power analysis (Zar 1984), using an estimate of variance of larval abundances in 1986 and 1987, indicated that, for a power of 0.8 and 0.95 , a sample size of 50 stations per pass would detect overall mortality rates of 0.029 and $0.037 \mathrm{~d}^{-1}$, respectively. These appeared to be reasonable lower limits of larval mortality which might be expected.

A stratified survey design was used for both passes. A stratification scheme for the first survey of the area (Pass 1) was based on prior information. Historically, high densities of larvae have been observed between Sutwik Island and the Semidi Islands (Fig. 1a). We also expected high densities in the inshore area north of Sutwik Island. Five strata were included in Pass 1 (Fig. 1a). The 7 strata for the second survey (Pass 2, Fig. 1b) were determined from the shipboard counts of the larvae found in Pass 1. The high inshore abundances found in Pass 1 were predicted to move to the southwest with the prevailing current; therefore the Pass 2 survey was extended further to the southwest.

The cruise was conducted from the NOAA vessel 'Miller Freeman' between 19 May and 9 June 1988. A grid of stations 9 or $19 \mathrm{~km}$ apart was established as described above and refined based on larval surveys of prior years, and from results of egg and larval cruises in April and May 1988. This grid was occupied from 21 to 24 May (Fig. 1a, Pass 1) and was resampled from 1 to 6 June (Fig. 1b, Pass 2). The mean date of each pass was separated by $12 \mathrm{~d}$

Three sets of gear comparisons were done - on 20 May, 30 May and 6 June - to examine catch rates by fish size for an estimate of larval escapement and avoidance of gear. The gears tested were a $60 \mathrm{~cm}$ bongo net with $0.333 \mathrm{~mm}$ mesh, a $1 \mathrm{~m}$ Tucker trawl
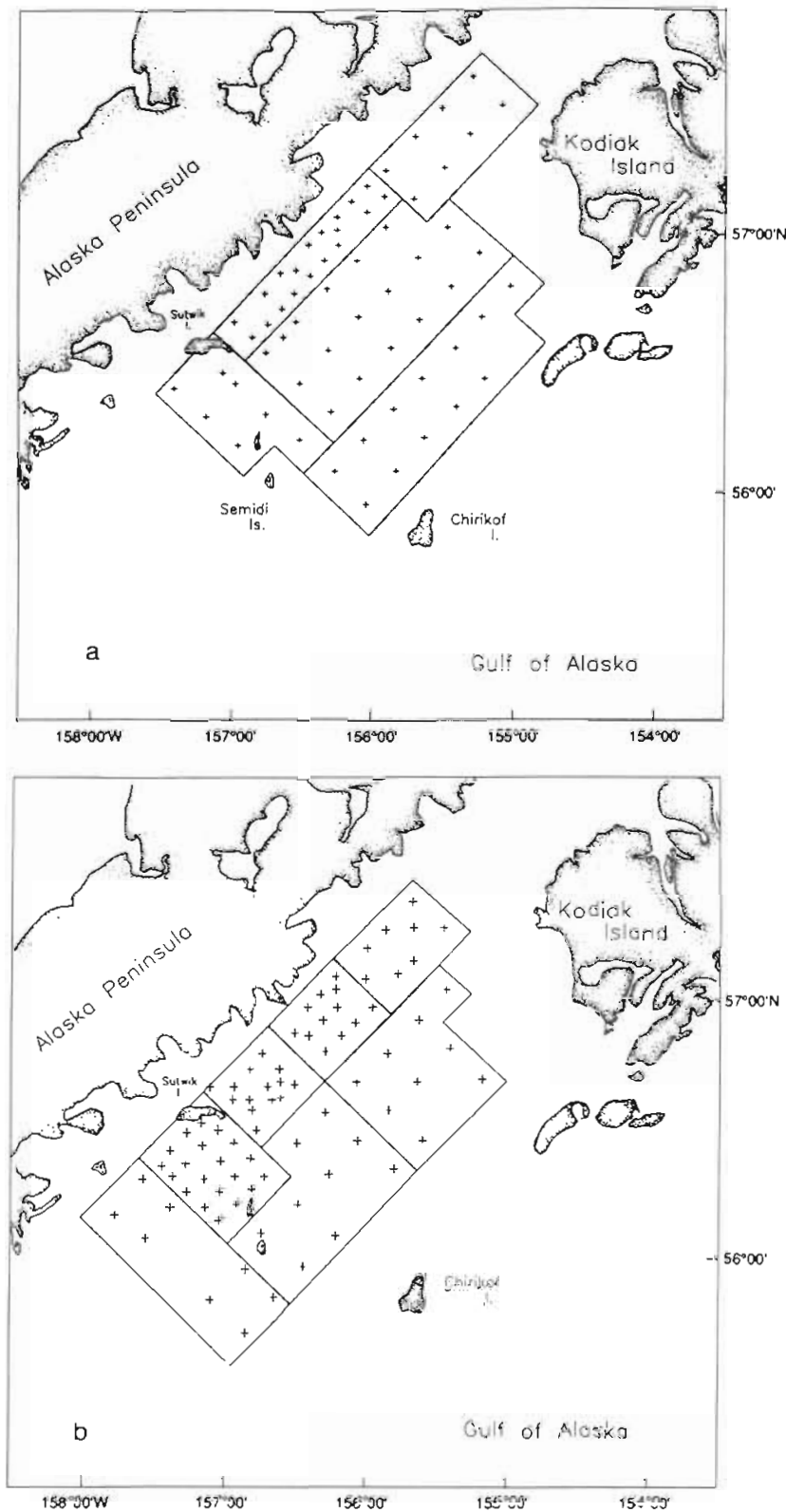

Fig. 1. Survey area for (a) Pass 1. and (b) Pass 2, including station locations and strata boundaries

with $0.505 \mathrm{~mm}$ mesh, a $3 \mathrm{~m}$ Tucker trawl with $1.5 \mathrm{~mm}$ mesh, and a Methot frame trawl with $2 \times 3 \mathrm{~mm}$ oval mesh (Methot 1986). This range of gear types and mesh sizes has been shown to catch walleye pollock ranging from ca 4 to $40 \mathrm{~mm}$ standard length (SL) (M. Shima \& K. Bailey unpubI.). Two daytime tows and 1 or 2 nighttime tows were done with each gear type Each set of gear comparisons was located in an area of relatively high (>250 larvae $10 \mathrm{~m}^{-2}$ ) abundance, and took ca 24 h to complete. All hauls for a particular set of gear comparisons were done at the same location. 
The first set of gear comparison tows (20 May) indicated that the Tucker trawl was the most efficient in catching the size range of larvae observed (4 to $15 \mathrm{~mm}$ SL). It was therefore chosen as the standard gear for the larval surveys. Oblique tows were done to a depth of $100 \mathrm{~m}$, as prior work has shown that larvae are above $100 \mathrm{~m}$ at this time of year (Kendall et al. 1987). The ship's speed was approximately 2 to 2.5 knots. A flow meter was used to normalize catch for volume filtered. The Tucker trawl was deployed with the net closed, and a messenger was sent to open the net when it reached sampling depth. The net was then retrieved at $20 \mathrm{~m} \mathrm{~min}^{-1}$

A subsample of walleye pollock larvae was removed from the cod end and immediately preserved for special studies. This subsample included larvae which were preserved in $95 \%$ ethanol for daily growth increment analysis. In order to find areas of high concentrations of larvae for further special studies and to find the boundaries of the larval distribution (to ensure that the complete larval distribution was sampled), a volumetric subsampling method was used on the remainder of the catch to estimate the total number of larvae. The remaining contents of the cod end, aside from larvae removed for special studies, were preserved in $5 \%$ buffered formalin. These samples were later resorted for a final count of walleye pollock larvae, which included those that had been removed for special studies.

Analytic methods. The number of larvae per tow was converted to number of larvae per $10 \mathrm{~m}^{2}$ using a standard haul factor (Smith \& Richardson 1977). Total number of larvae per pass was the sum over all strata of the stratum mean multiplied by the area of the stratum.

Gear comparisons: For each of the 3 sets of gear comparison tows, catch rates by larval size interval were compared among gear types to test whether significant numbers of small or large larvae were missed by the sampling gear, and to examine catching efficiency by larval size. The number of larvae per $10 \mathrm{~m}^{2}$ per $1 \mathrm{~mm}$ SL interval for each of the gear comparison tows was averaged by gear type. A Kolmogorov-Smirnov test (K-S; Zar 1984) was done to assess the difference in catch rates between the bongo net and the $1 \mathrm{~m}$ Tucker trawl.

An analysis of variance (ANOVA) of $1 \mathrm{~m}$ Tucker trawl catches was done to test whether catch rates differed between day and night (indicating gear avoidance). The catch per $10 \mathrm{~m}^{2}$ at each survey station was log-transformed to equalize the variance. The factors in the ANOVA were strata and day/night. Two strata from Pass 1 were excluded because they contained only stations done during the day.

Length-frequency and shrinkage: The standard length of 50 walleye pollock larvae per haul (Passes 1
\& 2) was measured from a combination of ethanolpreserved larvae, formalin-preserved larvae, and larvae measured before preservation. Larval lengths from each preservative type were combined in order to construct an unbiased length-frequency file. Biases by preservative type were due to selective removal of larvae (by size) for special studies. The number of larvae measured from each preservative type was proportional to the total number of larvae which had been placed in that preservative. Samples from each preservative type were random. Lengths of larvae from different preservative types were converted to fresh (pre-fixation) lengths using the following relationships:

$(95 \%$ ethanol $)$ Fresh length $=\frac{\text { Fixed length }-0.349}{0.900}$, and

$(5 \%$ formalin $)$ Fresh length $=\frac{\text { Fixed length }-0.097}{0.900}$.

These relationships were derived from experiments [in 1988 and other years; D. Seifert, Alaska Fisheries Science Center (AFSC), 7600 Sand Point Way NE, Seattle, WA 98115, USA, pers. comm.] where fresh length and preserved length were measured on the same fish. Converted lengths were combined into an overall length-frequency for each pass.

Aging: Approximately 15 to 20 fish per station from about 15 stations per pass were aged from otoliths by enumerating daily growth increments (Yoklavich \& Bailey 1990). Daily growth increments have been validated by laboratory studies for this species (Nishimura \& Yamada 1984, Bailey \& Stehr 1986). Growth was linear over the size range $(4.7$ to $18.2 \mathrm{~mm}$ ) examined $\left(\mathrm{R}^{2}=0.90\right)$.

An analysis of covariance (ANCOVA) was done to test differences in growth over the study period and area. The ANCOVA included length as a dependent variable, stratum as a categorical variable, and age as the covariate, and included an age-stratum interaction term. The analysis showed that the slope of the agelength regression (over the common range, 5 to $18 \mathrm{~mm}$ ) did not vary significantly among stations over the survey area $(p=0.919)$. Within each pass, pair-wise tests of the equality of the intercepts (using Bonferroni probabilities; Miller 1981) of the length-age regression among strata showed that within Pass 1, 4 of the 5 pairs of strata tested had the same intercept $(p>0.05)$, while 1 was statistically different $(p<0.05)$. However, this difference was small and we considered it insignificant. Within Pass 2, the intercepts were the same among strata. Growth rates within each pass were therefore treated as equal.

Mortality estimation: An age-length key (Kimura 1977 ) was computed for each pass. There were 309 larvae aged from Pass 1 and 249 larvae aged from 
Pass 2. The elements in each row ( $\mathrm{q}_{1 a}$ ) of the key are the proportion of fish in length interval $l$ that are age $a_{\text {, }}$ thus each row is the age distribution for the length interval. Each element in the matrix is used to estimate the proportion of length $I$ larvae in the population that are age $a$. Age and length intervals were chosen to cover the range of the aged larvae (length ranged from 3 to $22.5 \mathrm{~mm}$, age ranged from 6 to $62 \mathrm{~d}$.). The interval size must be large enough to contain enough larvae in the sample to produce reliable estimates of the true proportions in the population. In this application, length intervals of $0.5 \mathrm{~mm}$ were used. Daily ages were desired, but this resulted in too many age intervals for the number of aged larvae, so age intervals of $3 \mathrm{~d}$ were used. Additionally, the use of age intervals less than $3 \mathrm{~d}$ would not be justified as the measurement error in the aging process was $\pm 1 \mathrm{~d}$.

An age-length key was used for this study rather than an estimated age-length relationship for converting length-frequencies into age-frequencies. This is necessary because fish of a specific cohort may be missing from the population but could be misidentified in the length composition due to the averaging effect of the model. An age-length key preserves the shape of the age distribution present in the aged subsample, which is assumed to be a precise representation of the true age distribution if the aged subsample is unbiased.

The standardized catch of larvae at each station was partitioned into $3 \mathrm{~d}$ cohorts based on the length distribution at the station and the appropriate age-length key. Cohorts were defined by the age of the larvae on the mean date of the pass. For example, the mean date for Pass 2 was day-of-the-year (DOY) 155, so a larva sampled on DOY 153 with an estimated age of 22 to $24 \mathrm{~d}$ would be assigned to the 24 - to 26 -d-old cohort, its age on DOY 155. This age adjustment for the day of sampling was necessary because the duration of each pass ( 5 d) was longer than the duration of a cohort ( $3 d$ ).

The total number of larvae in each cohort for each pass was computed by summing the estimated cohort totals from each stratum. The cohort totals for each stratum were estimated by averaging the estimated number of larvae from each station in the cohort over stations, then multiplying the average by the total area of the stratum.

$$
\begin{gathered}
C_{h a}=\sum_{i} C_{h i a} \\
C_{h i a}=A_{h j} \sum_{j}^{N_{h i}} \frac{C_{h i a j}}{N_{h l}}
\end{gathered}
$$

where $C_{h a}=$ estimated abundance of cohort $a$ in Pass $h$; $C_{h r a}=$ estimated abundance of cohort $a$ in stratum $i$ in Pass $h ; C_{h i d}=$ estimated no. of larvae in cohort $a$ per $10 \mathrm{~m}^{2}$ at station $j$ in stratum $i$ in Pass $h ; A_{h i}=$ area of stratum $i$ in Pass $h$ in units of $10 \mathrm{~m}^{2}$; and $N_{h i}=$ no. of stations in stratum $i$ in Pass $h$.

The variance of the estimated cohort totals has 2 components: the variability about the standardized catch sizes within each stratum and the uncertainty about the age distribution. This uncertainty is due to using an age-length key to estimate the age of the larvae rather than measuring the age of each larva directly. Kimura (1977) estimated variance of an age distribution from an age-length key; however, in the present application, the age distribution variance was complicated by the fact that a cohort is comprised of larvae from different age intervals corresponding to the different sampling dates. Therefore, an estimator for the variance about a total of a range of ages was used (S. J. Picquelle, ASFC, pers. comm.). Covariance between the estimates for a cohort from the 2 passes is assumed to be zero because these estimates are taken from 2 surveys which are statistically independent.

Mortality rates were estimated for each $3 \mathrm{~d}$ cohort that was present in both passes. Cohorts represented by very few fish in the age-length key (i.e. very young and very old fish) were dropped from the mortality analysis, as they were suspected of being underrepresented in the catch. The mean dates of the 2 passes were separated by $12 \mathrm{~d}$. An exponential function was used to estimate cohort-specific mortality rates over the $12 \mathrm{~d}$.

$$
\begin{gathered}
C_{2, a}=C_{1, a} \mathrm{e}^{-z_{a}\left(t_{2}-t_{\mathrm{l}}\right)} \\
z_{\alpha}=\frac{\ln \left(C_{1, a}\right)-\ln \left(C_{2, a}\right)}{t_{2}-t_{1}}
\end{gathered}
$$

where $z_{a}=$ estimated instantaneous daily mortality rate for cohort $a ; t_{2}-t_{1}=$ time between passes $(12 \mathrm{~d})$; $C_{1, a}=$ estimated abundance of cohort $a$ in Pass $1_{i}$ and $C_{2, a}=$ estimated abundance of cohort $a$ in Pass 2.

This model was also used to calculate the instantaneous daily mortality rate for the combined 10 April to 16 May cohorts.

The variance of the mortality rate was estimated using the delta method (Seber 1982).

$$
\operatorname{Var}\left(z_{a}\right) \approx \frac{1}{\left(t_{2}-t_{1}\right)^{2}}\left[\frac{\operatorname{Var}\left(C_{1, a}\right)}{C_{1, a}^{2}}+\frac{\operatorname{Var}\left(C_{2, a}\right)}{C_{2, a}^{2}}\right]
$$

where $\operatorname{Var}\left(Z_{a}\right)=$ approximate estimate of variance about the mortality rate for cohort $a_{i}$ and $\operatorname{Var}\left(C_{h, a}\right)=$ estimate of the variance about the estimated abundance of cohort $a$ in Pass $h$ (Picquelle pers. comm.).

The significance of the mortality coefficients could have been tested with a simple t-test, however, the variance of the mortality rate is an approximation. Therefore, the significance of the mortality rate was inferred through the use of a test of the difference in 
abundance of each cohort between Passes $1 \& 2$. This was a 2-tailed test where the variances of the abundances were not assumed to be equal and the critical value for the test was a weighted average (Sokal \& Rohlf 1981).

Biases to the mortality estimates caused by advective transport into or out of the study area were examined by a model of advection and diffusion developed for this area (P. Stabeno \& L. Incze, NOAA, Pacific Marine Environmental Laboratory (PMEL), 7600 Sand Point Way NE, Seattle, unpubl. data). The model is a 2dimensional (depth-integrated) finite difference model with an imposed velocity field, that contains terms for larval mortality and age-dependence:

$\frac{\partial C}{\partial t}=-U \frac{\partial C}{\partial x}-V \frac{\partial C}{\partial y}-K_{H}\left(\frac{\partial^{2} C}{\partial x^{2}}+\frac{\partial^{2} C}{\partial y^{2}}\right)-Q(a, x, y, t)$

where $C=$ the depth-integrated concentration of larvae; $t=$ time; $U=$ cross-strait horizontal velocity; $x=$ cross-strait axis; $V=$ along-strait horizontal velocity; $y=$ along-strait axis; $K_{\mathrm{H}}=$ horizontal coefficient of eddy diffusivity; $Q(a, x, y, t)=$ the larval source and sink term (i.e. hatching and mortality); and $a=$ larval age.

The concentration of larvae was assumed constant normal to the model boundaries $[C(x, y, t)=0]$. The horizontal velocities and coefficient of eddy diffusivity (which is assumed constant) were determined using drift buoy and current meter data. The only biological input into this model was an age-dependent mortality which enters via the $Q(a, x, y, t)$ term.

Larval concentrations measured during Pass 1 were used as initial input to the model. The age-dependent mortality used was from Yoklavich \& Bailey (1990). The model was run for $12 \mathrm{~d}$ with the mean observed current field (as derived from satellitetracked buoys; P. Stabeno \& R. Reed, NOAA, PMEL, unpubl. data). The percent of larvae expected in the region covered in Pass 2 was predicted from the model output. For the mortality estimation, survey boundaries for Pass 2 were adjusted to reflect the area where more than $95 \%$ of the larvae were predicted to be by the model $12 \mathrm{~d}$ after the mean date of Pass 1.

As an alternative, mortality rates derived from the age composition within each pass were also calculated via catch curve analysis (Ricker 1975) for comparison to those derived from the 2 passes. Assumptions made when using this method are that production of fish of all ages is constant, that mortality rate for all ages is also constant, and that all ages are equally vulnerable to sampling gear. Total mortality rates, over all ages, from the catch curves within each. pass were calculated from a regression of log abundance on age:

$$
\ln \left(C_{h a}\right)=\alpha_{h}-z_{h} t_{a}
$$

where $C_{h a}=$ estimated abundance of cohort $a$ in Pass $h$; $t_{a}=$ age of cohort $a ; \alpha_{h}=$ intercept for Pass $h ; z_{h}=$ estimated instantaneous daily mortality rate for Pass $h$.

Larval drift: Larval spatial distributions were contoured separately for each $3 \mathrm{~d}$ cohort for each pass. These plots were examined for patterns of distribution and for evidence that part of the larval distribution might have been missed in either Pass 1 or Pass 2 (indicated by high concentrations of larvae near the survey boundaries), thereby biasing the mortality estimates. Drift of larvae between Passes 1 \& 2 was measured by assuming coherence of 3 major observed larval patch features, and by measuring the net movement of these patches between the passes.

Centroids, a measure of the center of mass of the larval distribution computed by using abundances at each station weighted by the locations of the stations (Kendall \& Picquelle 1990), were calculated for all larvae from each pass. Centroid locations were corrected for irregular sampling distribution (with more stations in the inshore areas) by weighting each station location not only by larval density, but also by the area each station represented. Net displacement of the centroids of larval distribution was calculated for the interval between the 2 passes.

The 2 estimates of larval drift (from patch displacement and centroid displacement) were compared to the estimates of upper-water-column movement derived from a satellite-tracked drift buoy that was released in an area of larval concentration near the Alaska Peninsula during Pass 1.

\section{RESULTS}

\section{Day/night catch comparison and catchability}

Catch rates of walleye pollock larvae did not vary significantly between day and night (ANOVA, $\mathrm{p}=$ 0.56 , Table 1). There was no consistent pattern of catch in the day or the night. The strata effect was highly significant (ANOVA, $p=0.0003$, Table 1).

Table 1. Analysis of variance of log-transformed catch rates (no. of larvae $10 \mathrm{~m}^{-2}$ ) of the $1 \mathrm{~m}$ Tucker trawl using strata and day/night as factors

\begin{tabular}{|lcccc|}
\hline Source & df & Mean square & $F$ & $p$ \\
\hline Strata & 9 & 2.7509 & 3.89 & 0.0003 \\
Day/night & 1 & 0.2462 & 0.35 & 0.5562 \\
Interaction & 9 & 0.8936 & 1.26 & 0.2639 \\
Error & 112 & 0.7064 & & \\
\hline
\end{tabular}


The catch rates of the bongo and the $1 \mathrm{~m}$ Tucker trawl did not differ significantly (K-S test, $\mathrm{p}=0.89$ ). Other work on catchability of larvae by these gear types (Shima \& Bailey unpubl. data) has also shown no consistent pattern of differing efficiency over this larval size range. The gear comparison experiments showed that the $1 \mathrm{~m}$ Tucker trawl was effective in catching the entire length-range of larvae that were caught by the other gear (Fig. 2). The $3 \mathrm{~m}$ Tucker trawl and the Methot trawl caught less than the bongo and the $1 \mathrm{~m}$ Tucker because of their large mesh sizes. There were not significant numbers of smaller larvae in the $0.333 \mathrm{~mm}$ mesh bongo, or larger larvae in the larger mesh $3 \mathrm{~m}$ Tucker or Methot trawls. Therefore, no correction of abundance estimates for escapement or avoidance was made to the survey station catches made with the 1 m Tucker trawl.

\section{Model of advection and diffusion}

Estimates of probable changes in larval distribution derived from the application of the advection and diffusion model resulted in dropping the 2 northernmost stations from the Pass 2 survey. Larvae found at these 2 stations would have been upstream of the survey area in Pass 1 and therefore would have been advected into the Pass 2 survey area. Otherwise, the boundaries for Pass 2 were not changed, as the model predicted that more than $95 \%$ of the larvae found in Pass 1 would be found within the area covered during Pass 2.

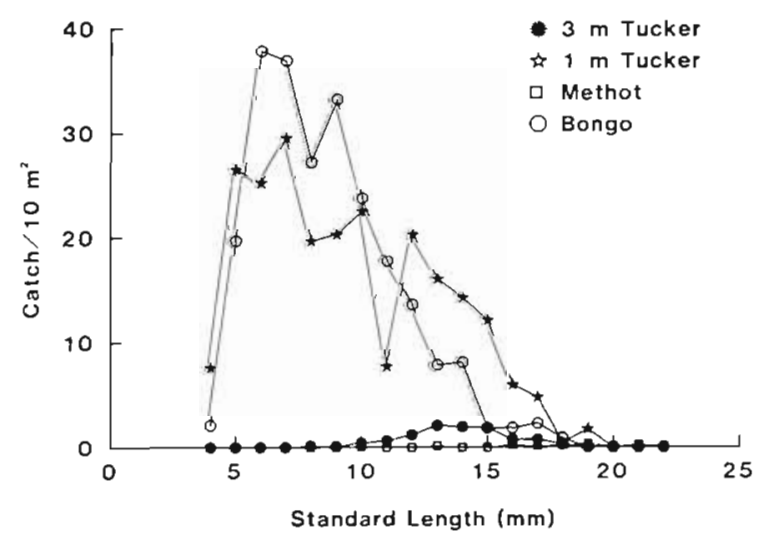

Fig. 2. Theragra chalcogramma. Comparison of catch at length of walleye pollock larvae averaged over all hauls from the 4 gear types
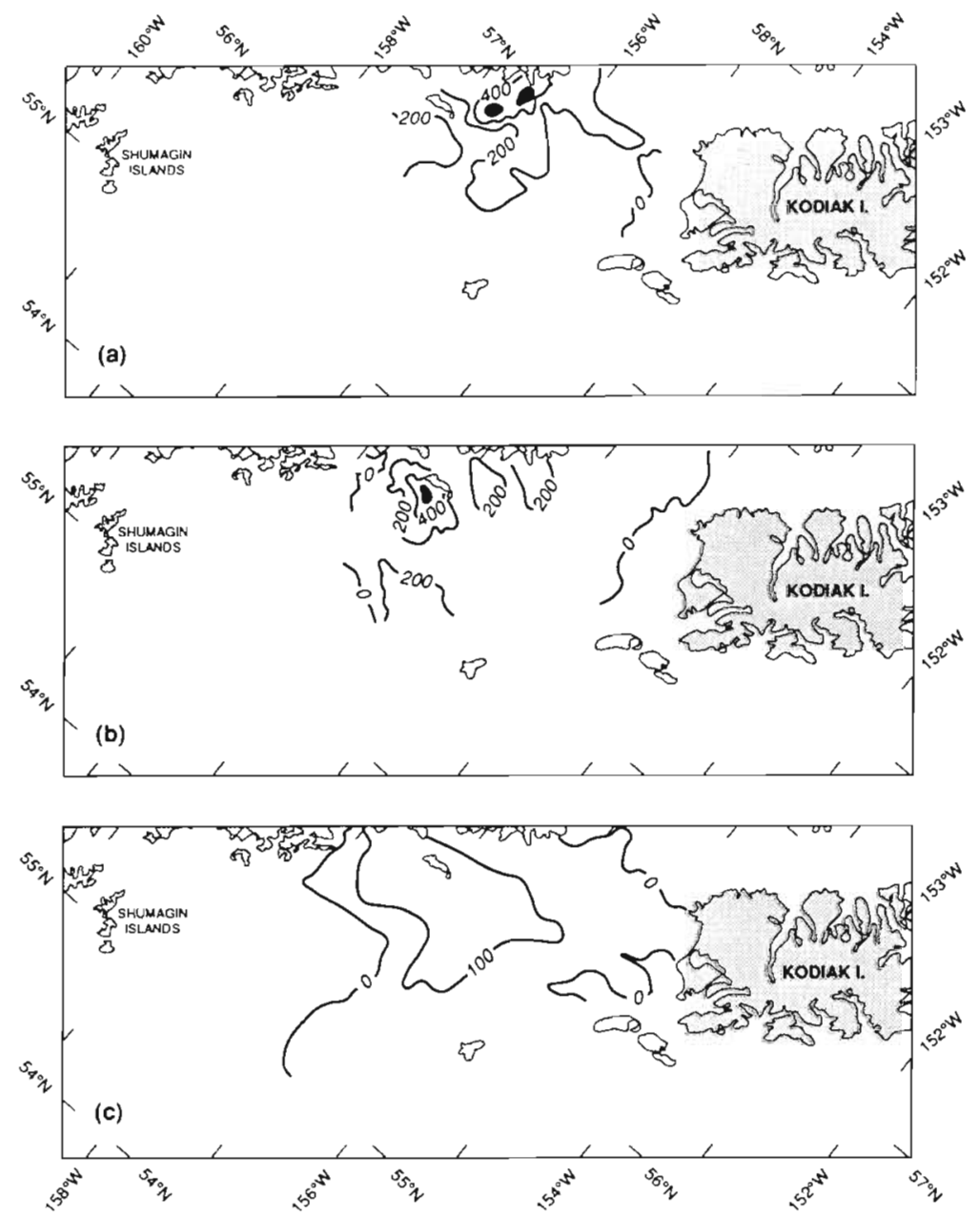

Fig. 3. The domain of the model is shown. Distribution of larvae (a) found during Pass 1 (this is the initial condition for the model), (b) found during Pass 2, and (c) predicted by the model of advection and diffusion for the time period corresponding to Pass 2. Larval abundance contours shown are ind $10 \mathrm{~m}^{-2}$ (solid area: $>600$ larvae $10 \mathrm{~m}^{-2}$ )

Comparison of the larval concentrations predicted from the model and those observed on the second survey (Fig. 3) shows that patch structure observed in the field was not preserved due to diffusion in the model, for all reasonable values of diffusivity $\left(K_{H}>5\right.$ $\left.\times 10^{5} \mathrm{~cm}^{2} \mathrm{~s}^{-1}\right)$.

\section{Mortality rates}

Abundances of the 10 April through 16 May cohorts were used to estimate mortality rates. Abundances for the 10 through 28 April cohorts were very similar between Passes 1 \& 2 . Abundances of fish with hatch dates between 1 and 16 May showed a clear decline in abundance from the first to the second pass (Fig, 4).

The instantaneous daily mortality rates $(z)$ for the separate $3 \mathrm{~d}$ cohorts ranged from -0.0574 to $0.0757 \mathrm{~d}^{-1}$ 


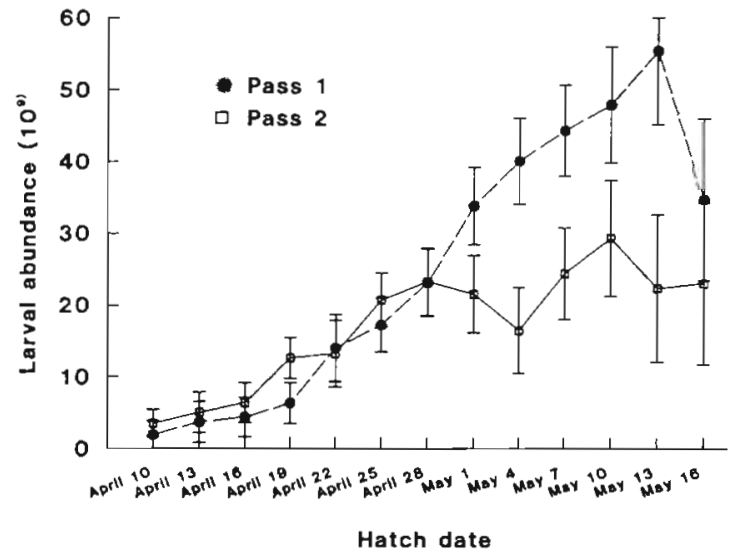

Fig. 4. Theragra chalcogramma. Larval abundance for $3 \mathrm{~d}$ cohorts during Passes 1 and 2

(Table 2). The instantaneous daily mortality rate for the combined 10 April to 16 May cohorts was $z=0.033 \mathrm{~d}^{-1}$ $(\operatorname{Var}(z)=0.0013)$. This mortality rate was not significantly different from zero $(t=0.92, \mathrm{p}>0.20)$.

Inspection of the cohort distributions for Pass 1 (Fig. 5) showed an area of relatively high concentration of larvae from the 10 to 19 April cohorts on the northwest side of the survey area near the Alaska Peninsula, which might not have been fully sampled. This was of interest due to the fact that the mortality rate estimated for these 4 cohorts were negative (Table 2). To test whether a significant number of larvae might have been missed in the inshore area during Pass 1 (which would have lowered the mortality rates for these cohorts), the northwest boundary of the survey area was redrawn closer to the Alaska Peninsula, increasing the total survey area for Pass 1. Larval abundances were extrapolated to the new boundary, and mortality rates recalculated using new total cohort abundances for Pass 1. The results of this analysis showed that, unless unusually high abundances of larvae were present in the nearshore areas outside the Pass 1 grid, extension of the survey area would not have been sufficient to raise the estimates of the mortality rates for these cohorts above zero (Table 3 ).

The overall daily mortality rate for each pass derived from the catch curve analysis was $z=0.0838 \mathrm{~d}^{-1}$ for Pass 1, and $z=0.0421 \mathrm{~d}^{-1}$ for Pass 2 .

\section{Larval drift}

Three main areas of concentration of larvae are visible in the distribution of the combined 10 April to 16 May cohorts in Pass 1 (Fig. 6a). Two patches were found to the northeast of Sutwik Island near the Alaska Peninsula ('Patch 1' and 'Patch 2'), and one was found to the northeast of the Semidi Islands ('Patch 3'). Three concentrations of larvae also are visible in Pass 2 (Fig. 6b), one to the northeast of Sutwik Island ('Patch 1'), one to the southwest of Sutwik Island ('Patch $2^{\prime}$ ), and one to the south of the Semidi Islands ('Patch 3'). Most of the $3 \mathrm{~d}$ cohorts were present in all 3 of these main patches in each pass.

There was an apparent southwestward displacement of all 3 patches over the interval between passes. By assuming the coherence of these 3 patches and measuring their displacement between the 2 passes, we could use their net movement over this time period as an estimate of the rate of larval drift. The time

Table 2. Theragra chalcogramma. Larval abundances and instantaneous daily mortality rates, $z_{1}$ (derived from 2 passes over the survey area) of 10 April to 16 May cohorts

\begin{tabular}{|c|c|c|c|c|c|c|c|c|}
\hline \multirow{3}{*}{$\begin{array}{l}\text { Hatch } \\
\text { date }\end{array}$} & \multicolumn{2}{|c|}{ Age $(d)$} & \multicolumn{4}{|c|}{ Abundance of larvae in survey area } & \multirow[t]{3}{*}{$z\left(\mathrm{~d}^{-1}\right)$} & \multirow[t]{3}{*}{$\mathrm{SE}$} \\
\hline & \multirow[t]{2}{*}{ Pass 1} & \multirow[t]{2}{*}{ Pass 2} & \multicolumn{2}{|c|}{ Pass 1} & \multicolumn{2}{|c|}{ Pass 2} & & \\
\hline & & & Numbers & $\mathrm{SE}$ & Numbers & SE & & \\
\hline $10 \mathrm{Apr}$ & 42 & 54 & $1.971 \times 10^{9}$ & $1.891 \times 10^{9}$ & $3.564 \times 10^{9}$ & $2.569 \times 10^{9}$ & -0.0494 & 0.1000 \\
\hline $13 \mathrm{Apr}$ & 39 & 51 & $3.718 \times 10^{9}$ & $2.845 \times 10^{9}$ & $5.043 \times 10^{9}$ & $3.486 \times 10^{9}$ & -0.0254 & 0.0859 \\
\hline $16 \mathrm{Apr}$ & 36 & 48 & $4.381 \times 10^{9}$ & $2.749 \times 10^{9}$ & $6.365 \times 10^{9}$ & $3.191 \times 10^{9}$ & -0.0311 & 0.0669 \\
\hline $19 \mathrm{Apr}$ & 33 & 45 & $6.336 \times 10^{9}$ & $2.845 \times 10^{9}$ & $1.261 \times 10^{10}$ & $4.875 \times 10^{9}$ & -0.0574 & 0.0494 \\
\hline $22 \mathrm{Apr}$ & 30 & 42 & $1.400 \times 10^{10}$ & $4.656 \times 10^{9}$ & $1.322 \times 10^{10}$ & $4.128 \times 10^{9}$ & 0.0048 & 0.0380 \\
\hline 25 Apr & 27 & 39 & $1.721 \times 10^{10}$ & $3.752 \times 10^{9}$ & $2.070 \times 10^{10}$ & $5.480 \times 10^{9}$ & -0.0154 & 0.0286 \\
\hline $28 \mathrm{Apr}$ & 24 & 36 & $2.308 \times 10^{10}$ & $4.712 \times 10^{9}$ & $2.323 \times 10^{10}$ & $5.631 \times 10^{9}$ & -0.0005 & 0.0264 \\
\hline 1 May & 21 & 33 & $3.384 \times 10^{10}$ & $5.401 \times 10^{9}$ & $2.151 \times 10^{10}$ & $5.205 \times 10^{9}$ & 0.0377 & 0.0242 \\
\hline 4 May & 18 & 30 & $4.008 \times 10^{10}$ & $5.991 \times 10^{9}$ & $1.646 \times 10^{10}$ & $4.018 \times 10^{9}$ & 0.0742 & $0.0239^{\circ}$ \\
\hline 7 May & 15 & 27 & $4.430 \times 10^{10}$ & $6.377 \times 10^{9}$ & $2.435 \times 10^{10}$ & $5.016 \times 10^{9}$ & 0.0499 & $0.0209^{*}$ \\
\hline 10 May & 12 & 24 & $4.788 \times 10^{10}$ & $8.078 \times 10^{9}$ & $2.930 \times 10^{10}$ & $6.166 \times 10^{9}$ & 0.0409 & $0.0225^{\circ}$ \\
\hline 13 May & 9 & 21 & $5.536 \times 10^{10}$ & $1.027 \times 10^{10}$ & $2.233 \times 10^{10}$ & $5.590 \times 10^{9}$ & 0.0757 & $0.0260^{\circ}$ \\
\hline $16 \mathrm{May}$ & 6 & 18 & $3.466 \times 10^{10}$ & $1.130 \times 10^{10}$ & $2.296 \times 10^{10}$ & $6.020 \times 10^{9}$ & 0.0343 & 0.0349 \\
\hline $\begin{array}{l}\text { Signifi } \\
\cdot \text { Signifi }\end{array}$ & $\begin{array}{l}\text { fferent } \\
\text { fferent }\end{array}$ & $\begin{array}{l}\operatorname{ro}\{\alpha= \\
\operatorname{ro}(\alpha=\end{array}$ & & & & & & \\
\hline
\end{tabular}




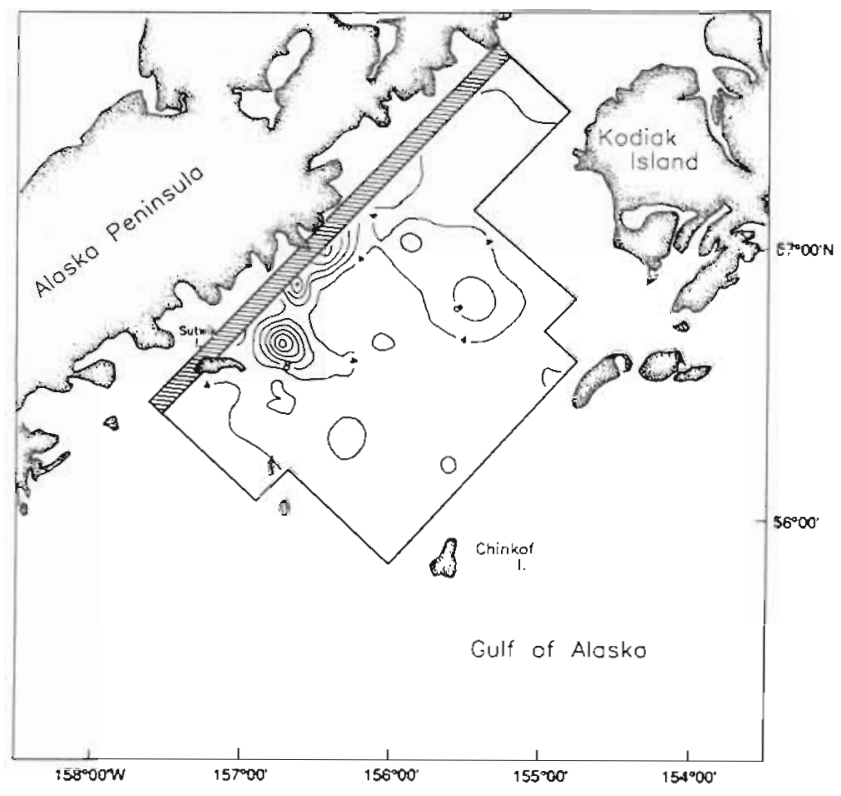

Fig. 5. Theragra chalcogramma. Distribution of the 19 April cohort during Pass 1 showing area on the northwest border of the survey area (shaded) where larvae might have been missed, causing underestimation of mortality rates. Larval abundance contours shown are ind. $10 \mathrm{~m}^{-2}$

period over which movement was estimated was between the actual sampling dates at each patch rather than between the mean pass dates. Drift was calculated from the straight-line movement of patches between the 2 dates.

Patch 1 movement averaged $2.59 \mathrm{~cm} \mathrm{~s}^{-1}$, Patch 2 averaged $3.61 \mathrm{~cm} \mathrm{~s}^{-1}$, and Patch 3 averaged $5.29 \mathrm{~cm} \mathrm{~s}^{-1}$. The average rate of drift for all 3 patches was $3.8 \mathrm{~cm} \mathrm{~s}^{-1}$.

Rates of drift were also estimated from displacement of the centroids of the entire larval distributions for each pass. The location of the centroids for 1988 in Passes 1 \& 2 were similar to 1981 and 1986 (Fig. 7). The centroid locations for 1979 and 1982 were further offshore. Centroid locations appear farther offshore than might be indicated by the distributions shown in the

Table 3. Theragra chalcogramma. Results of increasing Pass 1 survey area on the northwest side of the grid and recalculation of daily mortality rates of the 10 to 19 April cohorts

\begin{tabular}{|lccc|}
\hline Hatch date & $\begin{array}{c}\text { Mortality rate } \\
\text { (uncorrected) }^{\mathrm{a}}\end{array}$ & $\begin{array}{c}\text { Mortality rate } \\
\text { (corrected) }^{\mathrm{b}}\end{array}$ & $\begin{array}{c}\% \text { Change in } \\
\text { mortality rates }\end{array}$ \\
\hline $10 \mathrm{Apr}$ & -0.0494 & -0.0432 & $+12.5 \%$ \\
$13 \mathrm{Apr}$ & -0.0254 & -0.0174 & $+31.5 \%$ \\
$16 \mathrm{Apr}$ & -0.0311 & -0.0217 & $+30.2 \%$ \\
$19 \mathrm{Apr}$ & -0.0574 & -0.0462 & $+19.7 \%$ \\
${ }^{a}$ Using original Pass 1 survey boundary & \\
${ }^{\mathrm{b}}$ Using extended Pass 1 survey boundary \\
\hline
\end{tabular}

contour plots because the few high stations represented in the patches do not have a large impact on centroid locations, whereas they are interpolated over a larger area in the contour plots. The displacement of the centroids over the $12 \mathrm{~d}$ between mean pass dates suggests a rate of drift of $3.9 \mathrm{~cm} \mathrm{~s}^{-1}$.

The net movement of the satellite-tracked buoy was compared to these 2 estimates of larval drift. The buoy was deployed on 24 May, near the center of Patch 1 (which was sampled at approximately this time) (Fig. 8). The buoy location on 31 May was close to the center of Patch 1 when it was sampled during Pass 2 (on 1 June). If only the period 24 May to 1 June was considered (corresponding approximately to the interval between the passes), the average velocity was $4.7 \mathrm{~cm} \mathrm{~s}^{-1}$.

\section{DISCUSSION}

Estimating larval mortality rates for marine fish is difficult due to the many sources of sampling bias and error. In this study, we have attempted to avoid many of the problems which have complicated earlier studies. Use of multiple surveys instead of the more usual catch curve analysis made it possible to avoid the assumptions of constant egg production and constant mortality. Comparisons of several gear types and day/night sampling indicated that retention and escapement of walleye pollock larvae from sampling gear was not a problem. Transport of larvae through the sampling area was accounted for by sampling virtually the entire distribution of walleye pollock larvae, and boundaries were refined through the use of a model of advection and diffusion developed for this area. By analyzing daily growth increments of otoliths, we avoided the uncertainty of using length as a proxy for age, ensured that the same cohorts were identified in each survey, and were able to estimate mortality rates for specific $3 \mathrm{~d}$ cohorts of larvae. Ageing also made it possible to truncate the range of cohorts that had estimated mortality rates to those that were adequately sampled in each pass. Also, Somerton \& Koyabashi (1992) show that truncating the age distribution avoids bias due to low capture probabilities. Larvae hatched after completion of the first pass could also be excluded this way. Since virtually the complete vertical and horizontal distribution of larvae was sampled in this study, differences in spatial distribution of larvae, for example with age, were not a factor.

The range of mortality rates estimated from this study $(-0.0574$ to 0.0757$)$ was low compared to other published mortality rates for walleye pollock during this developmental 

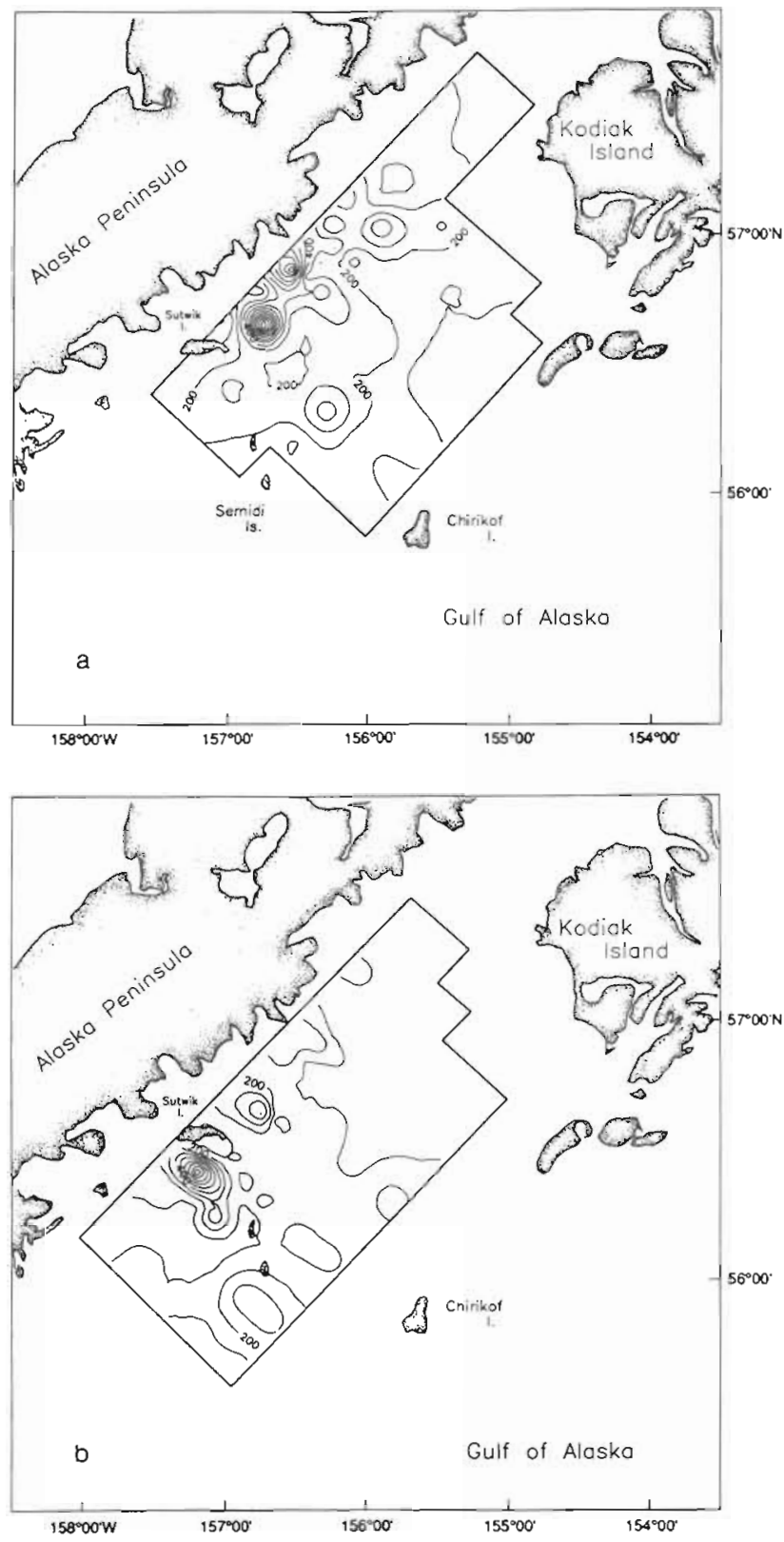

Fig. 6. Theragra chalcogramma. Distribution of 10 April to 1 May cohorts during (a) Pass 1 and (b) Pass 2. Larval abundance contours shown are ind. $10 \mathrm{~m}^{-2}$

period. Rates from prior studies have ranged from $z=$ 0.065 to $0.11 \mathrm{~d}^{-1}$ (Table 4). Estimates of mortality rates reported for the larval stage of other gadoids have also been also somewhat higher (e.g. for Atlantic cod: $z=$ $0.08 \mathrm{~d}^{-1}$, Houde 1987; and $z=0.12 \mathrm{~d}^{-1}$, Sundby et al. 1989). The fact that the daily mortality rates for all of the $3 \mathrm{~d}$ cohorts were consistently low with none exceeding $z=0.0747 \mathrm{~d}^{-1}$ and that mortality rates determined from catch curve analysis were also low supports the conclusion that the low overall mortality rates found in this study were realistic.
In accordance with the low mortality rates observed for larvae, there is evidence that 1988 may be a relatively strong year-class for walleye pollock spawned in Shelikof Strait. There was a high relative abundance of 0 -age juveniles caught in an August-September 1988 juvenile survey (Bailey \& Spring 1992) indicating that recruitment was established early. Furthermore, the 1988 year-class has made a strong showing in the annual March hydroacoustic surveys of the Shelikof spawning stock in both 1990 and 1991 (Hollowed et al. 1991; J. Traynor, AFSC, pers. comm.). Low larval mortality rates during the spring of 1988 could have been a contributing factor to the strength of the year-class.

It is interesting to note that wind speeds during May of 1988 were much lower than normal for an extended period of time including the time period of this survey. The mean May wind speed (derived from atmospheric pressure gradients estimated from National Meteorological Center data) for 1988 was $4.63 \mathrm{~m} \mathrm{~s}^{-1}$, whereas the average for May of 1980 to 1987 and 1989 was $6.70 \mathrm{~m} \mathrm{~s}^{-1}$.) The mechanism explaining a relationship between wind speed and larval survival is not known, although several authors have speculated on possible causal relationships in other species (Lasker 1975. Sundby \& Fossum 1989, MacKenzie \& Leggett 1991).

Based on the power test done previously, we did not expect to resolve mortality rates below $0.037 \mathrm{~d}^{-1}$ (for a power of 0.95 ). The 4 significant mortality rates were all greater than this $\left(0.041\right.$ to $\left.0.067 \mathrm{~d}^{-1}\right)$. Mortality rates of 9 of the 13 oldest cohorts were not significantly different from zero. There are several possible reasons for this. First, patchiness in the larval distribution could have caused the variance to be too large to make low mortality rates indistinguishable from zero. Better stratification and increased sampling in areas of high abundance could have reduced this source of variability. However, the patchy distribution of larvae and the uncertainty in predicting areas of high larval abundance make survey design difficult. Second, the fact that each pass was not synoptic (i.e. each took from 4 to $6 \mathrm{~d}$ to complete) and that the pass duration was greater than the duration ( $3 \mathrm{~d}$ ) of each cohort caused an increase in the variance in the age-length key, as it was a composite from several days. Adding more passes and more days between the passes would be alternative ways to increase our ability to detect low rates of mortality. Third, there is high natural variation in the age-length relationship. A larger ageing sample would be helpful in reducing this source of variation. And fourth, although we tried to eliminate the possibility of advection of larvae into the survey area between Passes $1 \& 2$ through the survey design and use of the model of advection and diffusion, it is still possible that such immigration did occur. 


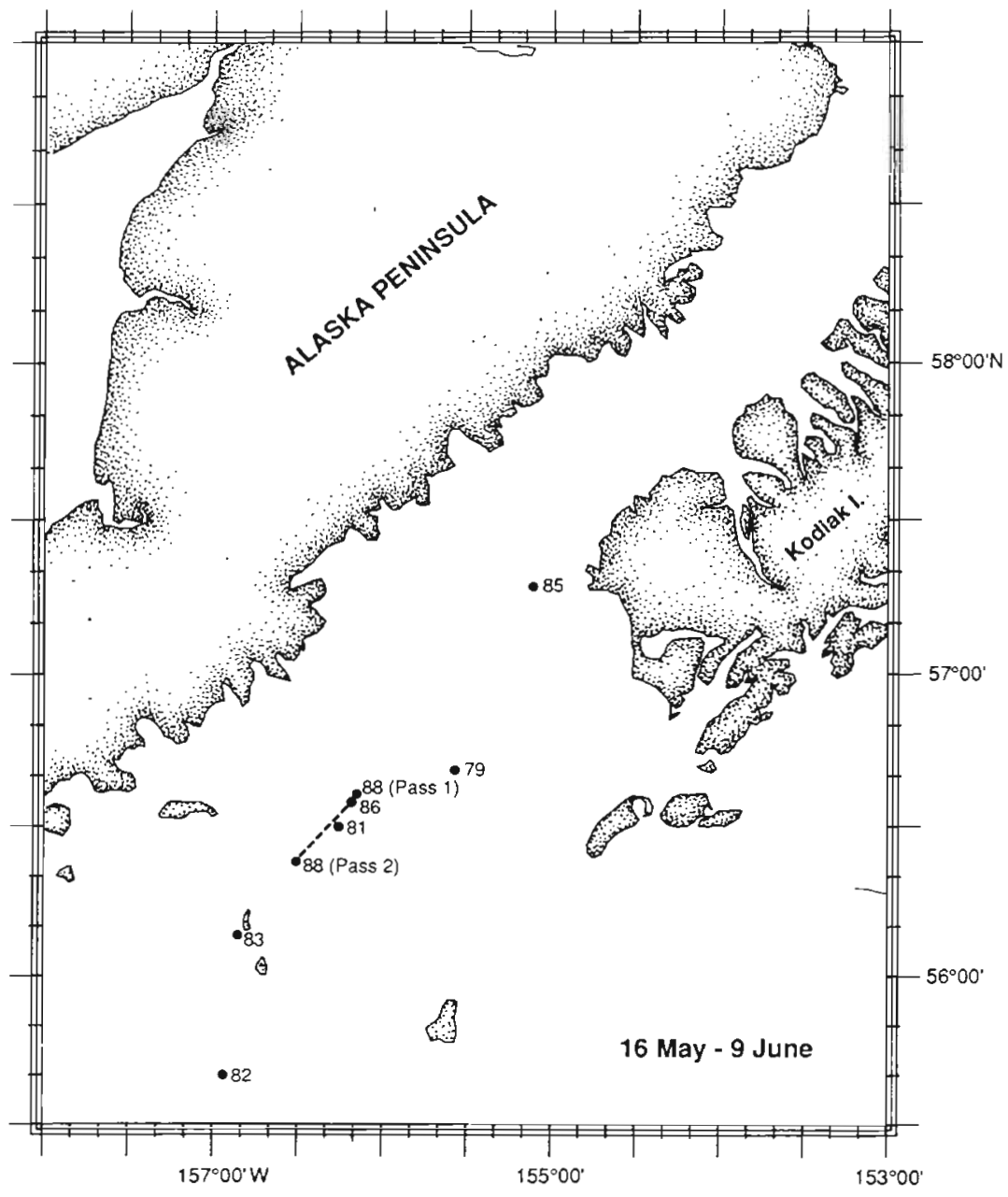

Fig. 7. Theragra chalcogramma. Centroids of larval distributions in Passes 1 and 2 (May 1988), as compared with other years (figure adapted from Kendall \& Picquelle 1990)

Table 4. Theragra chalcogramma. Estimates of instantaneous daily mortality rates $(z)$ for walleye pollock from Shelikof Strait from prior studies

\begin{tabular}{|c|c|c|}
\hline Source & $z$ & Comments \\
\hline Incze \& Campbell (1989) & 0.11 & \\
\hline $\begin{array}{l}\text { Yoklavich \& } \\
\text { Bailey (1990) }\end{array}$ & 0.08 & $\begin{array}{l}\text { Average of } 4 \text { to } \\
65 \text { d-old-larvae } \\
\text { sampled in June }\end{array}$ \\
\hline Kim (1987) & $\begin{array}{l}0.096 \\
0.082\end{array}$ & $\begin{array}{l}4-5 \mathrm{~mm} \text { cohort } \\
8-9 \mathrm{~mm} \text { cohort }\end{array}$ \\
\hline Kirn \& Bang (1990) & 0.070 & \\
\hline Kim \& Gunderson (1989) & 0.086 & \\
\hline Reed et al. (1989) & 0.065 & Within a larval patch \\
\hline$(\operatorname{Var}(z)$ & $\begin{array}{c}0.033 \\
0.0013)\end{array}$ & $\begin{array}{l}\text { For combined } 10 \mathrm{Apr} \\
\text { to } 16 \text { May cohorts }\end{array}$ \\
\hline
\end{tabular}

It is interesting to note that the 4 significant mortality rates were for cohorts of young larvae. Mortality rates actually are probably higher for young fish. A decrease in mortality rate with age or size is to be expected (Cushing 1974), and has been reported for walleye pollock larvae by Yoklavich \& Bailey (1990)

The mortality rates for the older cohorts were very low, and this, combined with very high variance, made them statistically indistinguishable from zero. The lack of significance of the mortality rates for older cohorts could also be explained by an underestimation of the abundance of older larvae during Pass 1 or an overestimation during Pass 2, either of which would have caused an apparent decrease in the mortality rate (or negative rates). There was no increase in the variance of the mortality rate relative to the mean with age, indicating that the distribution of older larvae was not patchier (which would have increased the variation in abundance estimates; Pielou 1977).

Transport of larvae was examined by displacement of larvae, by satellite drifter trajectories, and by satellite imagery. During the spring, daily mean current speeds in Shelikof Strait have been measured from 10 to $50 \mathrm{~cm} \mathrm{~s}^{-1}$ (Schumacher et al. 1989); however, the current structure in Shelikof Strait is complex in both time and space (Stabeno \& Incze unpubl.). Circulation is dominated by the Alaska Coastal Current (ACC), a narrow (less than $20 \mathrm{~km}$ wide), buoyancy-driven current system. There is much variability in current speeds and location and direction of the ACC within the study area (Reed et al. 1989). Eddy-like features on the order of $20 \mathrm{~km}$ in diameter are common and add complexity to the current structure. Due to the complex wind regime, regions of wind-driven convergence and divergence are common. Both eddies and regions of wind-generated convergence probably play a role in the observed patchiness of larvae.

Larval drift rates estimated by several different methods were all similar. The average drift rate from these 3 methods was ca 3.1 to $3.9 \mathrm{~cm} \mathrm{~s}^{-1}$. This rate is comparable to the larval drift rates estimated from other studies for larval walleye pollock (Incze et al. 1989: about $4 \mathrm{~cm} \mathrm{~s}^{-1}$; Kim \& Kendall 1989: $3.2 \mathrm{~cm} \mathrm{~s}^{-1}$; Reed et al. 1989: $5 \mathrm{~cm} \mathrm{~s}^{-1}$; Kim \& Bang 1990: $3.13 \mathrm{~cm}$ 


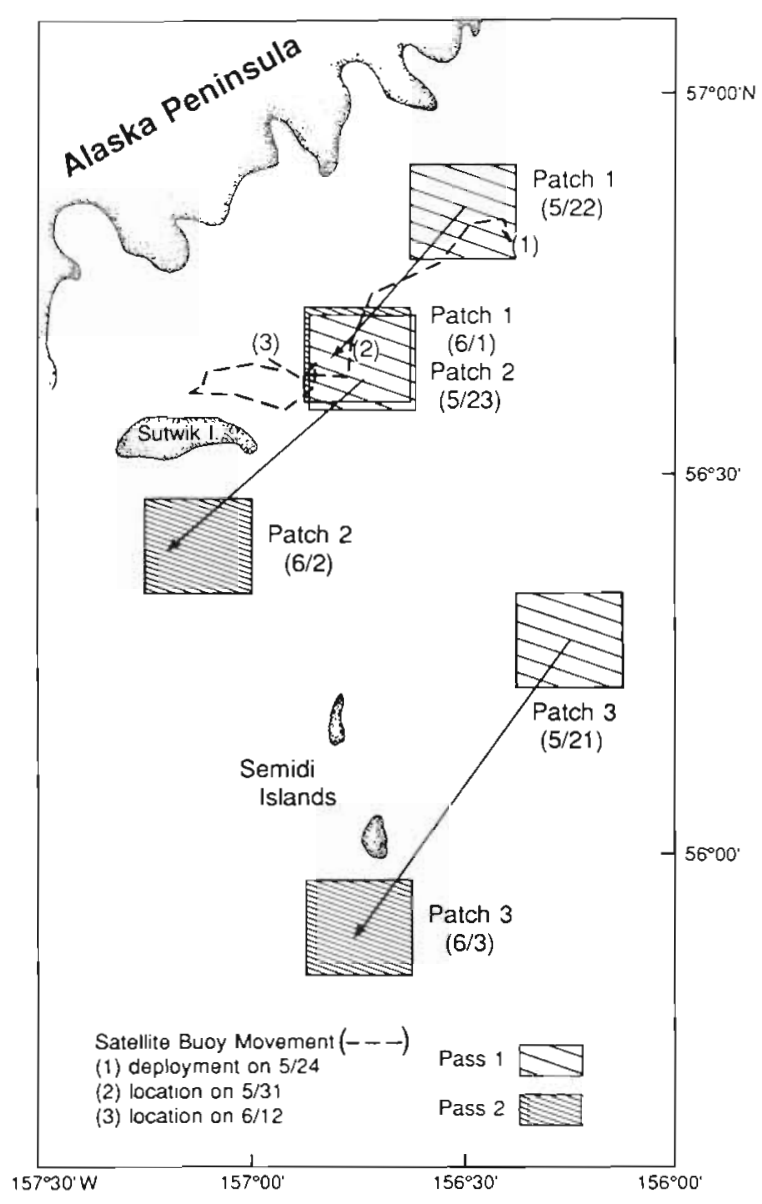

Fig. 8. Theragra chalcogramma. Boxes show the locations of the 3 main concentrations of larvae (as seen in Fig. 6a, b) and their net displacement between passes. The track of the satellite-tracked buoy is also shown

$\left.\mathrm{s}^{-1}\right)$. Other studies have estimated transport rates as high as 8 to $9 \mathrm{~cm} \mathrm{~s}^{-1}$ (Incze \& Campbell 1989, Incze et al. 1990).

Daily average velocities usually are weak $(<10 \mathrm{~cm}$ $\mathrm{s}^{-1}$ ) in the region near Sutwik Island and the Semidi Islands, the areas where the larval patches were found for this study. This flow is not in the ACC where currents can be as fast as $50 \mathrm{~cm} \mathrm{~s}^{-1}$. The low net drift of the larvae in the patches was small because they are not in the ACC. The model of advection and diffusion was able to retain larval patches if an eddy was included in the current field (Stabeno \& Incze unpubl.). Both cyclonic and anticyclonic eddies have been observed in the Shelikof Strait region several times during the past 5 yr (Vastano et al. 1992, Schumacher et al. 1993, Stabeno \& Incze unpubl.) and larval patches appear to be associated with these eddies.

Also, it is notable that there was no apparent alongstrait gradient of ages with older larvae further downstream, as might be expected if all cohorts were spawned in the same location (Kim \& Kendall 1989, Kendall \& Picquelle 1990) and no mechanism for retention of cohorts was present.

Inferences can be made about the patterns and velocities of surface flow based on sea surface temperature (SST) pattern displacements derived from satellite images (Vastano \& Borders 1984). A preliminary examination of SST patterns for the survey period in May of 1988 (A. C. Vastano, Dept. Oceanography, Texas A\&M Univ., College Station, TX 77843, USA, pers. comm.) showed a circulatory feature to the northeast of the Semidi Islands on May 23 to 24 and another to the south of the Semidi Islands on June 4 to 5 . The direction of flow between these 2 surface features would be consistent with the assumption of coherence between the larval patch feature found in this area. It is not clear from satellite images whether any circulatory features existed in the Sutwik Island area during our study that could have entrained the buoy and the larvae. The SST photographs do, however, indicate several significant meanders in the surface flow, particularly during the Pass 1 time period. The images also indicate a pattern of surface flow along the Alaska Peninsula near Sutwik Island in the same direction as the movement of the buoy and the inferred drift of Patches 1 \& 2

Larval patchiness may play a significant role in overall rates of larval mortality. Patch-level studies of larval growth, feeding and predation, and their importance to larval survival are being conducted for walleye pollock. The techniques described in this study will also continue to be used to obtain age-structured mortality rates, which, along with studies of the mechanisms and causes of larval mortality of walleye pollock in Shelikof Strait, will promote a better understanding of the dynamics of the recruitment process for this stock.

In summary, realistic and precise rates of larval pollock mortality were estimated for individual cohorts during the period of downstream drift in 1988. These estimates were low compared to those from other years, coinciding with calm ocean conditions during the larval drift period, and corresponding to relatively strong recruitment of the 1988 year class. These data reinforce the concept that good larval survival is a necessary, but perhaps not sufficient, factor for development of strong year-classes. Smaller and younger cohorts experienced significant mortality over the $12 \mathrm{~d}$ period between sampling dates, while mortality of older and larger cohorts was insignificant. The results support the concept of intra-specific size-dependent mortality.

Acknowledgements. This research is contribution number FOCI 0158 to NOAA's Fisheries Oceanography Coordinated Investigations. We thank Annette Brown, Nazila Merati and 
Stella Spring for assistance in the laboratory, Debbie Siefert for shrinkage data, Michiyo Shima for help with the gear comparisons, and other FOCI staff for general assistance. Drew Vastano gave useful advice on interpretation of the satellite imagery. The authors also thank Bob Francis, Anne Hollowed, Art Kendall, and Dave Somerton for their helpful comments on drafts of this manuscript.

\section{LITERATURE CITED}

Bailey, K. M., Spring, S. M. (1992). Comparison of larval, age- 0 juvenile and age-2 recruit abundance indices of walleye pollock, Theragra chalcogramma in the western Gulf of Alaska. ICES J. mar. Sci. 49: 297-304

Bailey, K. M., Stehr, C. L. (1986). Laboratory studies on the early life history of the walleye pollock. Theragra chalcogramma, (Pallas). J. exp. mar. Biol. Ecol 99: 233-246

Cushing, D. H. (1974). The possible density-dependance of larval mortality and adult mortality in fishes. In: Blaxter, J. H. S. (ed.) The early life history of fish. Springer-Verlag, Berlin, p. 103-112

Hewitt, R. P., Methot, R. D. (1982). Distribution and mortality of northern anchovy larvae in 1978 and 1979. CalCOFI Rep. 23: 226--245

Hinckley, S., Bailey, K. M., Picquelle, S. J., Yoklavich, M. M., Schumacher, J. D. (1990). Transport, distribution and abundance of larval and juvenile walleye pollock (Theragra chalcogrammal in the western Gulf of Alaska in 1987. Can. J. Fish. Aquat. Sci. 48: 91-98

Hollowed, A. D., Megrey, B. A., Munro, P., Karp, W. (1991). Walleye pollock. In: Stock assessment and fishery evaluation report for the 1992 Gulf of Alaska groundfish fishery. North Pacific Fishery Management Council, PO Box 103136, Anchorage, Alaska 99510, USA

Houde, E. D. (1987). Fish early life dynamics and recruitment variability. Am. Fish. Soc. Symp. 2: 17-29

Incze, L. S., Campbell, D. E. (1989). Estimation of ichthyoplankton (Theragra chalcogramma) mortality rates from a patch study: FOCI 1986. Tech. Rep. 72, Bigelow Laboratory for Ocean Sciences, West Boothbay Harbor, Maine 04575, USA

Incze, L. S., Kendall, A. W. Jr, Schumacher, J. D., Reed, R. K. (1989). Interactions of a mesoscale patch of larval fish (Theragra chalcogramma) with the Alaska Coastal Current. Cont. Shelf Res. 9: 269-284

Incze, L. S., Ortner, P., Schumacher, J. D. (1990). Microzooplankton, vertical mixing and advection in a larval fish patch. J. Plankton Res. 12: 365-379

Kendall, A. W. Jr, Clarke, M. E., Yoklavich, M. M., Boehlert, G. W. (1987). Distribution, feeding and growth of larval walleye pollock, Theragra chalcogramma, from Shelikof Strait, Gulf of Alaska. Fish. Bull. U.S. 85: 499-521

Kendall, A. W. Jr, Picquelle, S. J. (1990). Egg and larval distributions of walleye pollock Theragra chalcogramma in Shelikof Strait, Gulf of Alaska. Fish. Bull. U.S. 88: 133-154

Kim, S. (1987). Spawning behavior and early life history of walleye pollock, Theragra chalcogramma, in Shelikof Strait, Gulf of Alaska, in relation to oceanographic factors. $\mathrm{Ph} . \mathrm{D}$. dissertation, Univ. Washington, Seattle

Kim, S., Bang, B. (1990). Oceanic dispersion of larval fish and its implication for mortality estimates: case study of walleye pollock larvae in Shelikof Strait, Alaska. Fish. Bull. U.S. 88: 303-311

Kim, S., Gunderson, D. R. (1989). Cohort dynamics of walleye pollock in Shelikof Strait, Gulf of Alaska, during the egg and larval period. Trans. Am. Fish. Soc. 118: 264-273

Kim, S., Kendall, A. W. Jr (1989). Distribution and transport of larval walleye pollock (Theragra chalcogramma) in Shelikof Strait, Gulf of Alaska, in relation to water movement. Rapp. P.-v. Réun. Cons. int. Explor. Mer 191: $127-136$

Kimura, D. K. (1977). Statistical assessment of the age-length key. J. Fish. Res. Bd Can. 34: 317-32

Lasker, R. (1975). Field criteria for survival of anchovy larvae: the relation between inshore chlorophyll maximum layers and successful first feeding. Fish. Bull. U.S. 73: 453-462

MacKenzie, B. R., Leggett, W. C. (1991). Quantifying the contribution of small-scale turbulence to the encounter rates between larval fish and their zooplankton prey: effects of wind and tide. Mar. Ecol. Prog. Ser. 73: 149-160

Methot, R. (1986). Frame trawl for sampling pelagic juvenile fish. CalCOFI Rep. 27: 267-278

Miller, R. G. Jr (1981). Simultaneous statistical inference. Springer-Verlag, New York

Nishimura, A., Yamada, J. (1984). Age and growth of larval and juvenile walleye pollock, Theragra chalcogramma (Pallas), as determined by otolith daily growth increments. J. exp. mar. Biol. Ecol. 82: 191-205

Picquelle, S. J., Megrey, B. A. (in press). A preliminary spawning biomass estimate of walleye pollock, Theragra chalcogramma, in the Shelikof Strait, Alaska, based on the annual egg production method. In: Hunter, J., Lo, N. C. H., Fuiman, R. A. (eds.) Advances in estimating the biomass of fish stocks using ichthyoplankton. Symposium for annual meeting of the early life history section of the American Fisheries Society, June, 1991. Bull mar. Sci.

Pielou, E. C. (1977). Mathematical ecology. John Wiley \& Sons, New York

Reed, R. K., Incze, L. S., Schumacher, J. D. (1989). Estimation of the effects of flow on dispersion of larval pollock Theragra chalcogramma in Shelikof Strait, Alaska. In: Beamish, R. J., McFarlane, G. A. (eds.) Effects of ocean variability on recruitment and an evaluation of parameters used in stock assessment models. Can. Spec. Pub. Fish. Aquat. Sci. 1.08: 239-246

Ricker, W. E. (1975). Computation and interpretation of biological statistics of fish populations. Bull. Fish. Res. Bd Can. 191: 1-382

Schumacher, J. D., Stabeno, P., Bograd, S. (1993) Characteristics of an eddy over a continental shelf: Shelikof Strait, Alaska. J. geophys. Res. (in press)

Schumacher, J. D., Stabeno, P., Roach, A. T. (1989). Volume transport in the Alaska Coastal Current. Cont. Shelf Res. 9: $1071-1083$

Seber, G. A. F. (1982). The estimation of animal abundance. Oxford Univ. Press, New York

Smith, P. E., Richardson, S. L. (1977). Standard techniques for pelagic fish egg and larval surveys. FAO Fish. Tech. Pap 175: $1-99$

Sokal, R. R., Rohl, J. F. (1981). Biometry. W. H. Freeman \& Co., New York

Somerton, D. A., Koyabashi, D. R. (1992). Inverse method for mortality and growth estimation: a new method for larval fishes. Fish. Bull. U.S. 90:368-375

Sundby, S., Bjøke, H., Soldal, A. V., Olsen, S. (1989). Mortality rates during the early life stages and year class strength of the Arcto-Norwegian cod (Gadus morhua L.), Part II, Proc. of workshop on year class variations as determined from pre-recruit investigations, Sept. 28-30, 1988. Inst. Mar. Res., Bergen

Sundby, S., Fossum, P. (1989). Feeding conditions of ArctoNorwegian cod larvae compared to the Rothschild-Osborn theory on small-scale turbulence and plankton contact rates. J. Plankton Res. 12: 1153-1162 
van der Veer, H. W., Pihl, L., Bergman, M. J. N. (1990). Recruitment mechanisms in North Sea plaice Pleuronectes platessa. Mar. Ecol. Prog. Ser. 64: 1-12

Vastano, A. C., Borders, S. E. (1984). Sea surface motion over an anticyclonic eddy on the Oyashio front. Remote Sens Environ. 16: 87-90

Vastano, A. C., Schumacher, J. D., Incze, L. S. (1992). Observation and analysis of fishery processes: larval pollock at

This article was submitted to the editor
Shelikof Strait, Alaska. Fish. Oceanogr. 1: 20-31

Yoklavich, M. M., Bailey, K. M. (1990). Hatching period, growth and survival of young walleye pollock Theragra chalcogramma as determined from otolith analysis. Mar. Ecol Prog. Ser. 64: 13-23

Zar, J. H. (1984). Biostatistical analysis. Prentice-Hall, Inc. Englewood Cliffs, NJ

Manuscript first received: December 21, 1992

Revised version accepted: April 29, 1993 